\title{
Ethnic Inequalities in Overweight and Obesity Prevalence among Copenhagen Schoolchildren from 2002 to 2007
}

\author{
Dorthe Corfitzen Pedersen $^{a} \quad$ Julie Aarestrup ${ }^{a}$ Seija Pearson ${ }^{b}$ \\ Jennifer Lyn Bakera, c \\ anstitute of Preventive Medicine, Bispebjerg and Frederiksberg Hospital, Copenhagen, \\ Denmark; ${ }^{b}$ Pediatric Practice for Children and Adolescents, Helsingør, Denmark; ${ }^{c}$ Novo \\ Nordisk Foundation Center for Basic Metabolic Research, Faculty of Health and Medical \\ Sciences, University of Copenhagen, Copenhagen, Denmark
}

Key Words

Child $\cdot$ Ethnicity $\cdot$ Obesity $\cdot$ Overweight $\cdot$ Socioeconomic status

\begin{abstract}
Background: The stabilization in levels of childhood overweight has masked increasing gaps among different ethnic and socioeconomic groups in several countries. Objective: To examine if levels and trends in childhood overweight and obesity differed by ethnicity and socioeconomic areas in Copenhagen schoolchildren. Methods: From measured heights and weights of 32,951 children 5-8 and 14-16 years of age, the prevalence of overweight (including obesity) and obesity were estimated using International Obesity Task Force criteria. Differences in prevalence levels and trends across six school years by ethnicity and socioeconomic areas were examined using logistic regression. Results: The prevalence of overweight significantly decreased from 2002 to 2007 among the youngest Western girls and boys, showed no significant changes among the oldest non-Western girls and increased among the oldest nonWestern boys. In all years, the youngest non-Western children had significantly higher levels of overweight than Western children. Although the prevalence of overweight tended to be higher in low socioeconomic areas as compared with high socioeconomic areas, few differences were statistically significant. Consistent trends in overweight across the years by socioeconomic area were not observed. Conclusion: Ethnic and social inequalities exist in childhood overweight among Copenhagen schoolchildren; thus appropriate interventions targeting high-risk groups are needed

(C) 2016 The Author(s)

Published by S. Karger GmbH, Freiburg
\end{abstract}


Pedersen et al.: Ethnic Inequalities in Overweight and Obesity Prevalence among Copenhagen Schoolchildren from 2002 to 2007

\section{Introduction}

After decades of rapid increases in the prevalence of overweight and obesity among Copenhagen schoolchildren [1], a tendency towards a stabilization was observed from 2002 to 2007 [2]. A recent Danish study using data until 2010 found that this stabilization persisted and was evident across a wide range of child and adolescent ages [3]. These findings reflect a general trend that has been observed worldwide $[4,5]$.

Despite an overall stabilization in the prevalence of childhood overweight and obesity, an increased gap in the prevalence has been reported with children from ethnic minority populations being worse off than children from majority ethnic groups in different countries $[6,7]$. Additionally, studies from England, Sweden and the USA have reported social gradients, with the highest rates of overweight observed among children from the lowest socioeconomic status groups [7-9]. These findings suggest that it is warranted to consider both the ethnicity and socioeconomic status of children when monitoring trends in prevalence of overweight and obesity, as an overall stabilization could otherwise mask a potential widening gap among sub-groups within populations.

Currently, trends in the prevalence of childhood overweight and obesity are largely unknown among different ethnic and socioeconomic groups in Denmark. Therefore, we examined if trends in prevalence of overweight (including obesity) and obesity developed in heterogeneous manner among different ethnic and socioeconomic groups among Copenhagen schoolchildren 5-8 and 14-16 years of age during the school years of 2002 to 2007.

\section{Participants and Methods}

Subjects came from the Copenhagen School Health Records Register (CSHRR), which has previously been described in detail elsewhere [10]. In brief, Copenhagen children at public and private schools were offered health examinations at school entry and exit, which were performed by medical doctors during the years included in this study. During the examinations, the child's general health was evaluated and information was recorded on a health card and later computerized. Height was measured to the nearest $0.5 \mathrm{~cm}$ and weight to the nearest $0.5 \mathrm{~kg}$. Children were lightly clothed and not wearing shoes. The schools provided the equipment that was used, and it was not standardized.

In the school years from 2002/2003 to 2007/2008, 34,297 children participated in the health examinations. During the years included in this study, not all schools were visited each year, thus not all children were offered a health examination for administrative reasons [2]. The health examinations were required at school entry, but they were optional at school exit. Approximately $80 \%$ of Copenhagen schoolchildren had an examination at school entry, and approximately $60 \%$ had an examination at school exit [2]. To be eligible for this study, a child had to have information on the school they were measured at, age, sex, valid measures of height and weight, ethnicity, and not be adopted. These criteria were fulfilled by 33,150 children $(96.7 \%$ of the starting population). As in a previous study [2], the children were divided into a school entry group, covering children aged 5-8 years, and a school exit group, including those between 14-16 years of age. The small number of children who fell outside of these age ranges were excluded $(n=103)$.

At the health exam, children and/or their parents were asked to self-identify their ethnicity. More than 157 countries, world regions and ethnicities were reported. As many of these groups included few children, they were categorized into Western and non-Western groups based upon geography and guided by principles used by Denmark's National statistical service (supplementary table S1, available at $h$ ttp://content. karger.com/ProdukteDB/produkte.asp?doi=446482) [11]. As it is common in Denmark to use the term Arab to denote ethnicity rather than reporting a country of origin, this group was classified as a separate ethnic group belonging to the non-Western category. We categorized children with mixed ethnicities, but who had at least one Western parent as Western $(n=2,570)$. The length of the child's stay in Denmark was not assessed at the health exam, so it could not be taken into consideration. Children for whom their ethnicity could not be categorized were excluded $(n=92)$. 
Pedersen et al.: Ethnic Inequalities in Overweight and Obesity Prevalence among Copenhagen Schoolchildren from 2002 to 2007

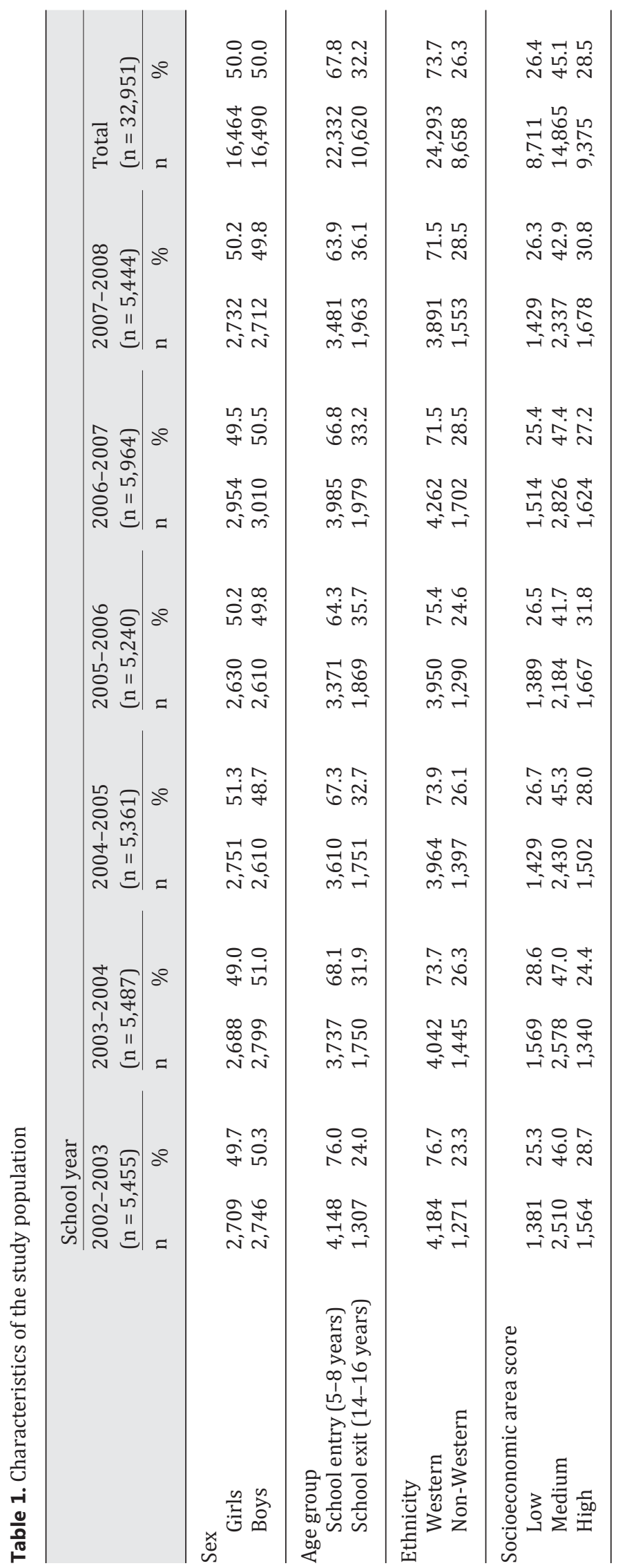


Pedersen et al.: Ethnic Inequalities in Overweight and Obesity Prevalence among Copenhagen Schoolchildren from 2002 to 2007

As a proxy for the socioeconomic status of the children, we calculated a score for the city district in which the school was located. We retrieved data from the Copenhagen Municipality on city districts according to average income, proportion of inhabitants with no or a short education and the proportion of unemployed inhabitants (excluding children, elderly, those on parental leave and students) [12]. Using the method of The Capital Region's health research center, these values were ranked in tertiles and then summed across the characteristics. Based upon the score, districts were classified as low, medium, or high socioeconomic status [13].

BMI was calculated for each child as weight $(\mathrm{kg})$ divided by the square of height $\left(\mathrm{m}^{2}\right)$. Children with extreme values for height, weight or BMI without an accompanying diagnosis in their record were excluded $(\mathrm{n}=4)$. The prevalence of overweight (including obesity) and obesity was calculated using the sex- and agespecific BMI cut-offs defined by the International Obesity Task Force (IOTF) [14]. These cut-offs correspond to the BMI cut-offs for adults (BMI $\geq 25 \mathrm{~kg} / \mathrm{m}^{2}$ for overweight (including obesity) and BMI $\geq 30 \mathrm{~kg} / \mathrm{m}^{2}$ for obesity). The prevalence of overweight (including obesity) and obesity were also assessed by the World Health Organization's (WHO) cut-off criteria for children aged 5-19 years (overweight > $1 \mathrm{z}$-score and obesity $>2$ z-scores) (supplementary tables S4-S7, available at http://content.karger.com/ProdukteDB/produkte. asp?doi=446482). Hereafter, the term overweight also includes obesity.

The associations between Western or non-Western ethnicity and socioeconomic area were tested by a chi square test. Potential interactions between ethnicity and socioeconomic area on overweight and obesity were tested by the likelihood ratio test within age groups and sex. Logistic regressions were used to test differences by each school year in the prevalence of overweight and obesity between the Western and nonWestern children, among the three largest ethnic groups (Danish, Arab and Turkish), and among three socioeconomic areas (low, medium and high). Western children, Danish children, or children from the high socioeconomic areas were used as the reference groups in the regressions. Time trends in the prevalence of overweight and obesity among Western and non-Western children, the three largest ethnic groups (Danish, Arab and Turkish), and the three socioeconomic areas (low, medium and high) were also examined by logistic regression. Overweight or obesity was the dependent variable and school year was the independent variable with 2002/2003 as the reference year. The analyses examining differences between the three socioeconomic area groups were adjusted for ethnicity. All analyses were conducted separately by entry and exit age groups and by sex. As appropriate, analyses were adjusted for multiple testing using Dunnett's test. Statistical significance was set at $\mathrm{p}<0.05$.

\section{Results}

In total, 32,951 (99.4\%) of the eligible children were included in the analyses. The distributions of age, sex, ethnicity, and socioeconomic status were stable across the 6 school years (table 1). Of the included children, 69.4\% $(n=22,878)$ were of Danish origin, 4.3\% $(n=1,415)$ were of other Western origins and $26.3 \%(n=8,658)$ were of non-Western origin. Among the non-Western children, the two largest ethnic groups were Arab $(n=2,339)$ and Turkish $(n=$ $1,530)$, together accounting for $45 \%$ of the non-Western group.

There was an association between ethnicity and the socioeconomic area score $(\mathrm{p}<0.001)$, with $35 \%$ of Western children and only $9 \%$ of non-Western children attending schools in high socioeconomic areas. Differences were also observed for schools in low socioeconomic areas; only $20 \%$ of Western but $46 \%$ of non-Western children attended these schools. There were no interactions between ethnicity and the socioeconomic area score on the prevalence of overweight or obesity in any of the age groups by sex (all $p>0.05$ ).

Among the youngest children, the prevalence of overweight and obesity was significantly higher among non-Western than Western children during all school years (all p $<0.01$ ) (fig. 1). In addition, the prevalence of both overweight and obesity significantly decreased during the school years of 2002-2007 among the youngest Western girls from 15.9 to $12.8 \%$ $(\mathrm{p}=0.03)$ and from 3.5 to $2.3 \%(\mathrm{p}=0.04)$, respectively (fig. 1). Likewise, the prevalence of overweight significantly decreased among the youngest Western boys from 12.2 to $9.1 \%$ ( $p=0.03)$, and a tendency, albeit non-significant, towards a decrease was observed in the 
Pedersen et al:: Ethnic Inequalities in Overweight and Obesity Prevalence among

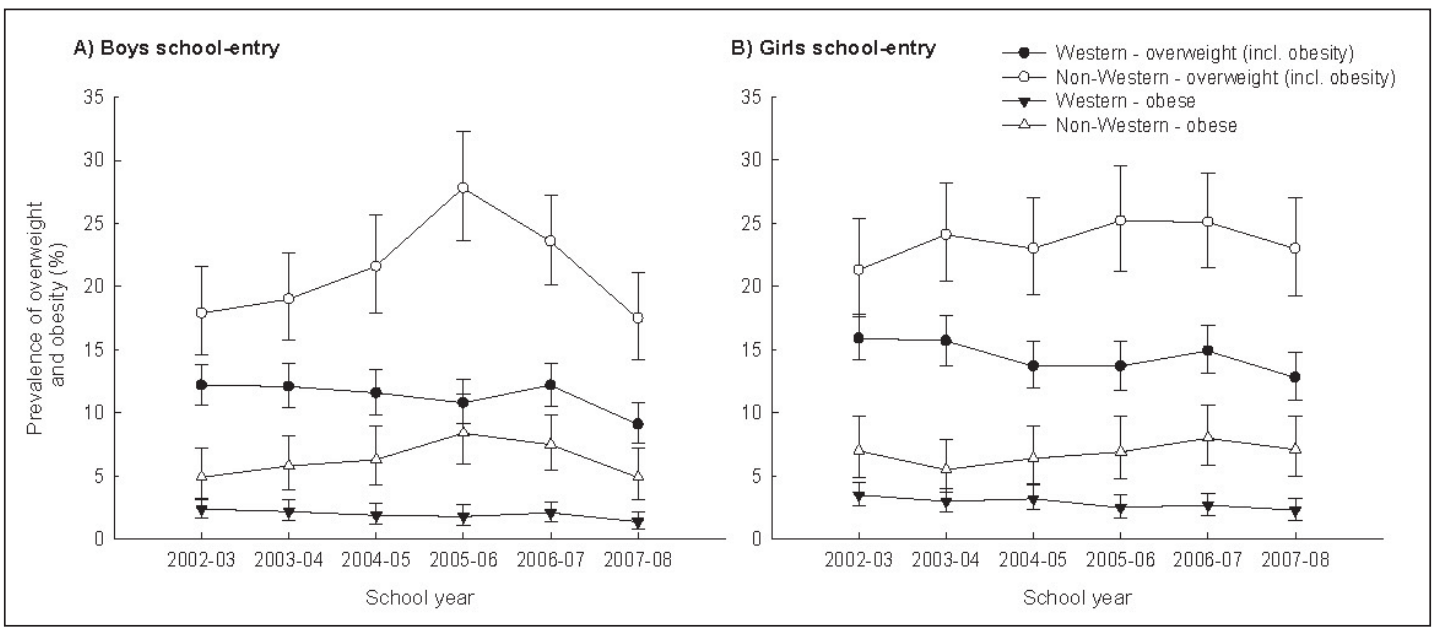

Fig. 1. Trends in prevalence of overweight and obesity in the ethnic groups at school entry across the six school years, $\mathbf{A}$ boys and $\mathbf{B}$ girls.

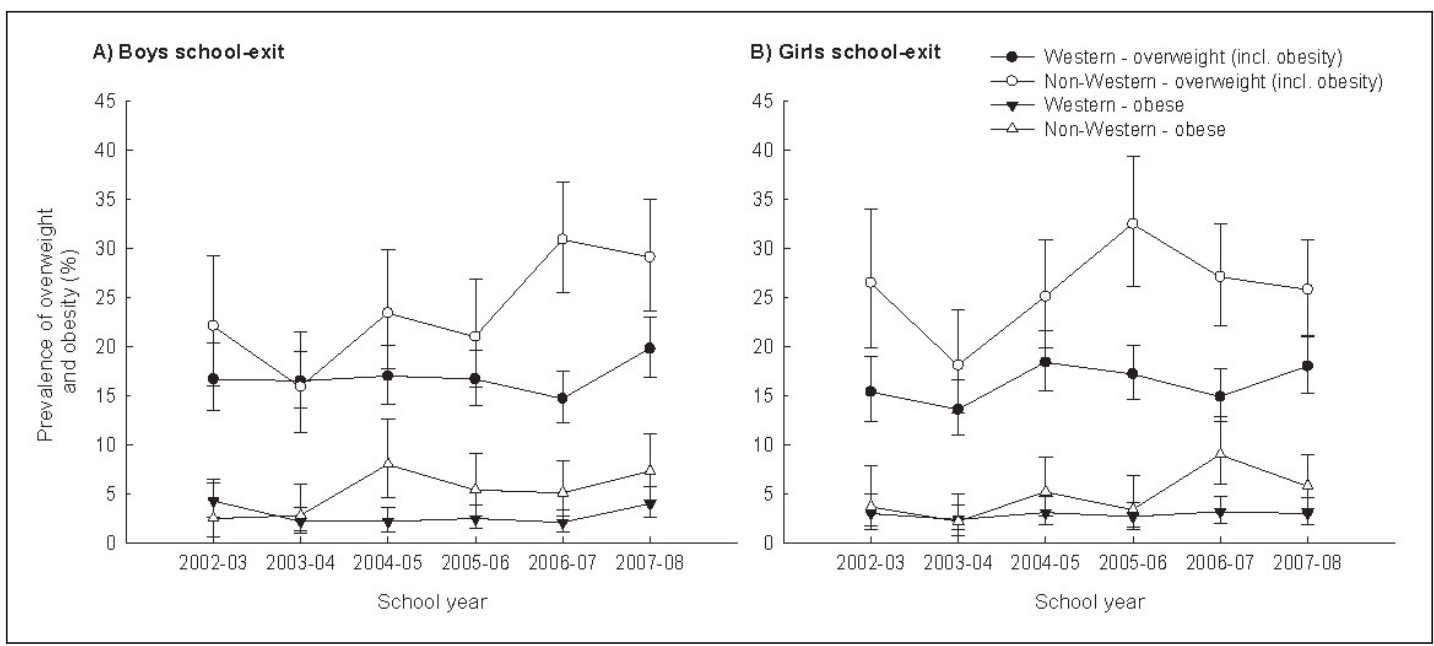

Fig. 2. Trends in prevalence of overweight and obesity in the ethnic groups at school exit across the six school years, $\mathbf{A}$ boys and $\mathbf{B}$ girls.

prevalence of obesity from 2.4 to $1.4 \%(\mathrm{p}=0.09)$. Statistically significant changes were not observed among the young non-Western girls or boys (fig. 1).

Similar to the youngest children, the prevalence of overweight and obesity were higher among the oldest non-Western children in most schoolyears compared with Western children (fig. 2). In contrast to the younger children, there were no significant changes in the prevalence of overweight and obesity among the older Western girls, Western boys and nonWestern girls. However, significant increases in the prevalence of both overweight and obesity were observed in older non-Western boys from 22.1 to $29.1 \%(\mathrm{p}<0.001)$ and from 2.5 to $7.3 \%(\mathrm{p}=0.04)$, respectively.

The sub-analysis in the three largest ethnic groups of Danish, Arab and Turkish children showed that among the younger children Turkish girls and boys generally had a significantly higher prevalence of overweight than Danish children across all of the school years (table 2). 
Pedersen et al.: Ethnic Inequalities in Overweight and Obesity Prevalence among Copenhagen Schoolchildren from 2002 to 2007

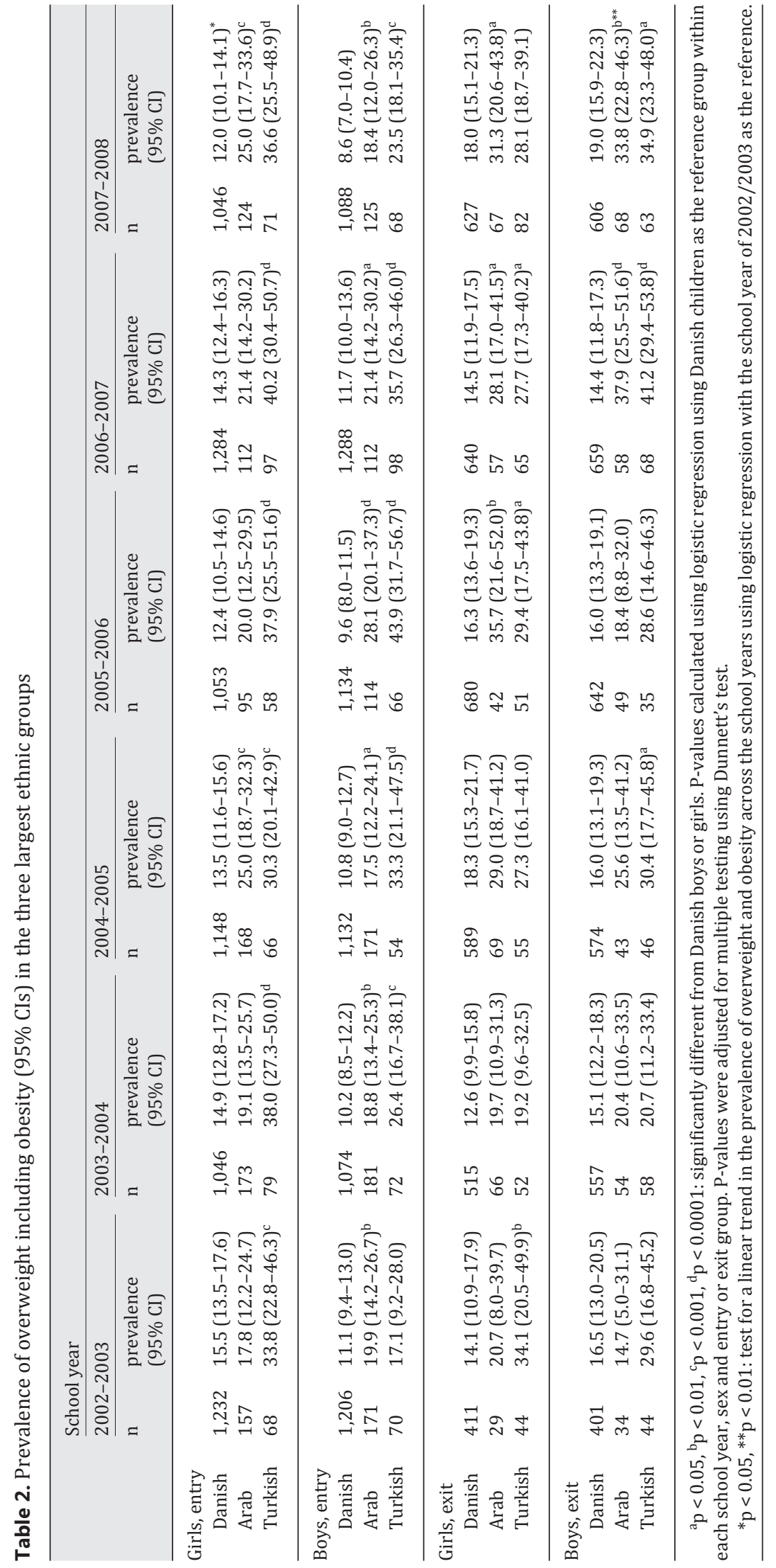


Pedersen et al.: Ethnic Inequalities in Overweight and Obesity Prevalence among Copenhagen Schoolchildren from 2002 to 2007

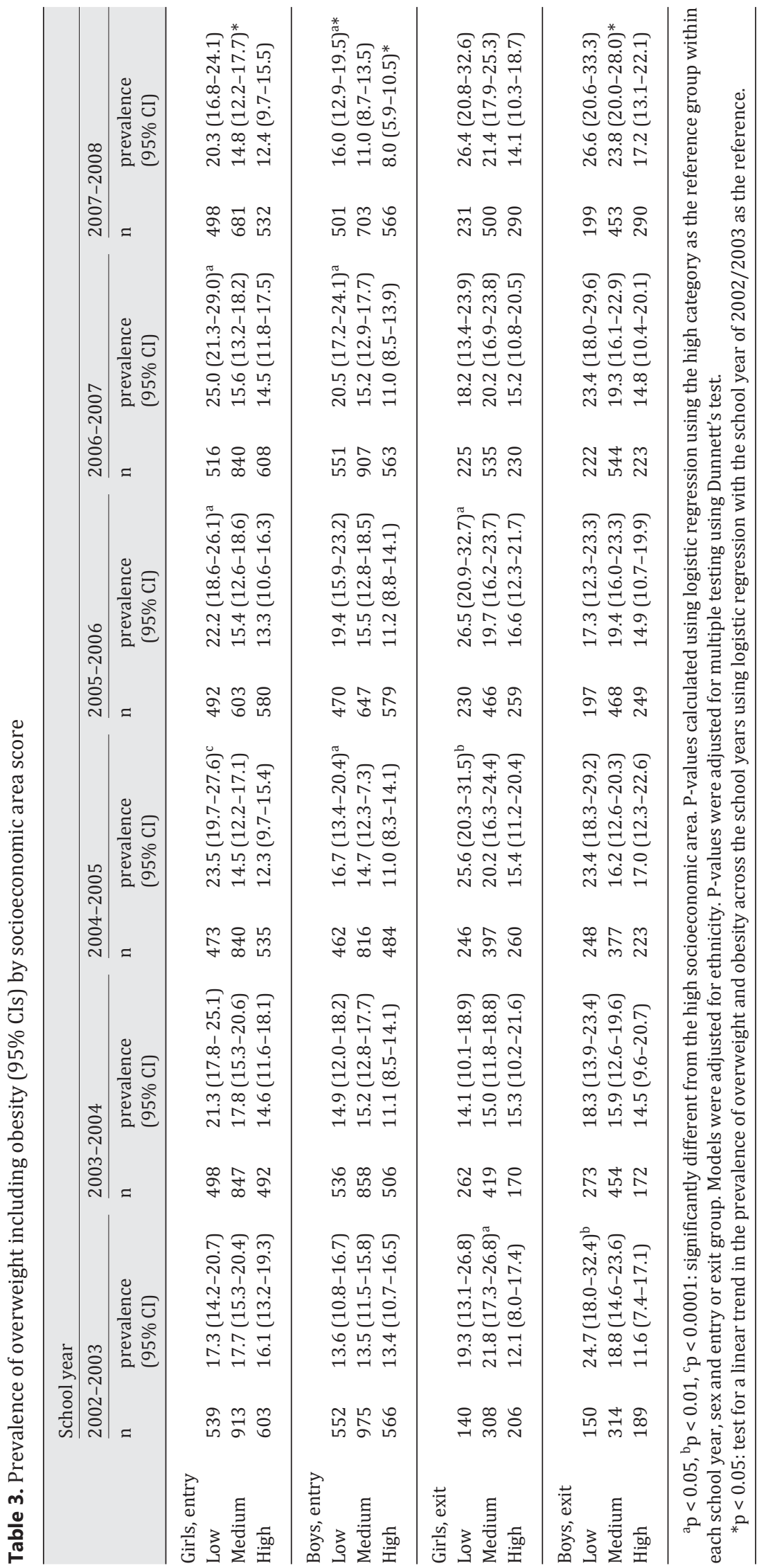


Compared with young Danish girls, young Arab girls also had statistically significantly higher levels of overweight in the school years of 2004/2005 and 2007/2008 (table 2). Compared with young Danish boys, young Arab boys also had a significantly higher prevalence of overweight during all school years (table 2). Among Danish girls at school entry, there was a statistically significant decrease in overweight across the school years (table 2). In the older age group, and likely due to low numbers of subjects in some of the groups, consistent patterns in the levels of overweight and obesity were not discernible. Among the older Arab boys there was a statistically significant increase in the prevalence of overweight across the school years (table 2). The results were largely similar when the prevalence of obesity was investigated (supplementary table S2, available at http://content.karger.com/ProdukteDB/produkte. asp?doi=446482).

The prevalence of overweight and obesity was also assessed in the three socioeconomic area groups. Compared with young girls in the high socioeconomic area, girls in the low socioeconomic area had a significantly higher prevalence of overweight in three school years $(2004 / 2005,2006 / 2006,2006 / 2007)$ (table 3). Similar results were found among the young boys (table 3). Among the youngest children, the prevalence of overweight significantly decreased in girls attending schools in medium socioeconomic areas and in boys attending schools in high socioeconomic areas from 2002/2003 to 2007/2008 (table 3). An increase in the prevalence of overweight was observed among boys attending schools in the low socioeconomic areas across these years (table 3). Consistent differences within each school year were not found for the older girls or boys by socioeconomic area (table 3). Statistically significant trends across the school years, however, were identified with increases in overweight found among boys in the medium socioeconomic area. Overall, the results were similar for the prevalence of obesity; however, the statistical significance of the trends disappeared for all socioeconomic areas (supplementary table s3, available at http://content.karger.com/ ProdukteDB/produkte.asp?doi=446482).

\section{Discussion}

Our results demonstrate that ethnic disparities exist in the prevalence of overweight and obesity in Copenhagen youth, especially among the youngest children. In all school years from $2002 / 2003$ to $2007 / 2008$, compared with the youngest children of Western origin, young children of non-Western origin had a higher prevalence of overweight and obesity. We found that the levels of overweight and obesity significantly decreased in the youngest Western children across these school years, but similar patterns were not detected in non-Western children. Among the older age group, non-Western children had a higher prevalence of overweight and obesity than Western children in most school years. Significant increases in the levels of overweight and obesity were only found among the older non-Western boys. Although there were indications of differences in the prevalence of overweight across the socioeconomic areas in some years, consistent patterns were not observed.

Denmark is regarded as an affluent country with a high degree of equality among its citizens, thus it is worrying that disparities in child overweight between ethnic groups exist even in this setting. In a previous study using the same population, we found that levels of overweight and obesity had stabilized during these school years [2]. However, when we examined these trends by ethnic group, we found the overall trend masked a widening gap in the prevalence of overweight and obesity between Western and non-Western children. Thus, the current study highlights how sub-groups of children may experience worsening health even if overall trends appear favorable. Our results furthermore emphasize the importance of accounting for childhood age; whereas the prevalence of overweight and obesity signifi- 
Pedersen et al.: Ethnic Inequalities in Overweight and Obesity Prevalence among Copenhagen Schoolchildren from 2002 to 2007

cantly decreased among the youngest Western boys and girls, an increase was observed among the oldest non-Western boys. Patterns were not apparent for older Western children and non-Western girls. It is notable that considerable ethnic differences in the prevalence of excess overweight and obesity already were present among the youngest children throughout the entire study period, as it suggests that these children are already set in a harmful weight trajectory even before they enter school.

Although ethnicity has been identified as a risk factor for overweight and obesity among Danish children, previous studies have not investigated trends across time. A study of Danish 5 - to 8-year-old children who lived in areas surrounding Copenhagen and who were measured in 2004/2005 found that children who spoke two languages at home (as an indicator of ethnicity) were significantly more likely to be obese than children speaking one language [15]. Evidence for differences in trends by ethnicity from other European countries is inconsistent. While the prevalence of overweight significantly increased from 1994 to 2000 in nonNordic adolescents living in Sweden, changes were not observed among their Nordic peers [16]. In contrast, no changes were reported between Western and non-Western children in Norway in a cross-sectional study carried out in 1999/2000 and again in 2005 [17]. Nonetheless, and similar to our results, these studies reported a higher prevalence of overweight among the non-Nordic/non-Western groups compared with the Nordic and Western groups $[16,17]$.

Compared with Danish children, those from the two largest ethnic groups of Arab and Turkish children had a higher prevalence of overweight in many of the school years. Similarly, a study from the Netherlands found a larger increase in the prevalence of overweight among Turkish children from 1999 to 2007, whereas the prevalence remained stable among native Dutch boys and decreased among native Dutch girls in the same period [6]. In a recent followup from 2007 to 2011, the prevalence of overweight had stabilized among the Turkish children as well, but considerable differences still existed, with Turkish children having the highest prevalence compared with native Dutch children [18].

Although we found indications of differences in the prevalence of overweight and obesity between children attending schools in low and high socioeconomic areas, few statistically significant trends across the school years were detected. Ethnicity was strongly associated with socioeconomic area in our sample as more non-Western children attended schools in low socioeconomic areas. It is possible that our indicator of socioeconomic status was not adequate for examining trends in child and adolescent overweight across the school years. Nonetheless, a previous study of 15-year-old Danish adolescents measured in 2007/2008 and 2008/2009 used a similar indicator of socioeconomic status and found that adolescents from lower socioeconomic municipalities in the greater Copenhagen area were significantly more overweight compared with those from better-off municipalities [19]. Other European studies have found increasing differences in the prevalence of overweight and obesity by socioeconomic status as well. However, consistent significant socioeconomic differences in the overweight prevalence across school years were only reported in France [20], whereas in Sweden and England significant social differences were only found in few years [8, 9], just as in our study.

Belonging to a non-majority ethnic group is a consistent indicator for the risk of childhood overweight and obesity. It persists at identifying children at risk of overweight and obesity in other studies even after accounting for several socioeconomic indicators and parental weight status [21], and other early life factors such as breastfeeding, maternal smoking, and birth weight [22]. Differences in the risk are established even before children enter school [23, 24]. Later in childhood, behavioral factors related to overweight have been found to differ among ethnic groups, and this may further explain why ethnicity is an indicator of overweight and obesity risk $[24,25]$. Along with our findings, these studies highlight that the ethnic differ- 
Pedersen et al.: Ethnic Inequalities in Overweight and Obesity Prevalence among Copenhagen Schoolchildren from 2002 to 2007

ences in childhood overweight and obesity are not simply explained by a single factor. Instead, they should be seen as a result of cultural, environmental, socioeconomic and biological factors working in a complex relationship [26].

The main strength of our study is the objective measurements of height and weight in a large multi-ethnic sample of school-aged children. Furthermore, the inclusion of data from six successive school years allowed us to evaluate trends in the prevalence of overweight and obesity, rather than the development between two time points, as reported in other studies. Due to administrative reasons, not all schools were visited each year. Documentation for these reasons is not available, but an examination of the pattern of school visits across the years did not reveal any differences by socioeconomic area of the city (not shown). Therefore, the prevalence estimates are likely to be representative for all Copenhagen schoolchildren. Copenhagen has a greater diversity of socioeconomic areas compared with other areas in Denmark, which could limit the generalizability of our findings [13]. Nonetheless, recent data on overweight and obesity prevalence showed that Copenhagen had lower or equivalent rates when compared to other municipalities in the Capital Region and Denmark as a whole $[13,27]$, indicating that the ethnic and social disparities in overweight and obesity prevalences might be worse in other areas. Ethnicity was provided by parents or self-identified in the older adolescents through reports of nationality, country of origin, ethnic group, and race. As such, there is the potential for misclassification, but it would likely lead to an attenuation of the results. Another limitation is the use of the socioeconomic area as a proxy for the socioeconomic status of the children as it was based upon where they attended school and not their home environment. Further, there is heterogeneity of socioeconomic status within the areas, they vary in size, and are often side-by-side. Although a more direct measure, such as parental education, would have been preferable, this information was not available. Nonetheless, as we did observe differences in the prevalence by socioeconomic area as did another Danish study using the same measure [19], it suggests that it captures some portion of social inequalities in the prevalence of overweight and obesity among Copenhagen schoolchildren. Our study is limited by a lower participation rate among the oldest schoolchildren compared with the younger children, as the health examinations are voluntary at the oldest ages. Thus, it is possible that there were higher levels of overweight and obesity as well as of children from lower socioeconomic areas and ethnicities other than Danish in the non-participating group as compared with those who did participate. Our study only examined data through the school year of $2007 / 2008$. Due to government-mandated changes to the school health care system, the regular examinations by school physicians that formed the basis for this study material are no longer offered, hence there is no possibility for further follow-up.

\section{Conclusion}

This study showed that even in an affluent country as Denmark considerable ethnic inequalities exist in the prevalence of overweight and obesity among schoolchildren. Overall trends have masked the increase in the disparities between children of Western and nonWestern origins. Differences in the prevalence also exist with respect to socioeconomic area, with children in the lower areas having the highest prevalence of overweight and obesity even though trends across the school years were not evident. Our findings stress the importance of including information on ethnicity and socioeconomic status of children when examining trends in overweight and obesity prevalences as the overall picture may mask important differences. Without these sorts of investigations, the most vulnerable groups of children with a high risk of overweight and obesity may not receive the help they need from targeted and appropriate public health interventions. 
Pedersen et al.: Ethnic Inequalities in Overweight and Obesity Prevalence among Copenhagen Schoolchildren from 2002 to 2007

\section{Acknowledgements}

DP, SP and JLB designed the study. DP carried out the analyses and wrote the first draft of the manuscript. JA provided statistical support during the analyses. All authors have been involved in interpretation of the analyses and made contributions to the final draft. All authors have approved the final version of the manuscript.

\section{Disclosure Statement}

The authors declare no conflicts of interest.

\section{References}

1 Pearson S, Olsen LW, Hansen B, Sørensen TIA: Stigning i overvægt og fedme blandt københavnske skolebørn i perioden 1947-2003. Ugeskr Læger 2005;167:158-162.

2 Pearson S, Hansen B, Sørensen TIA, Baker JL: Overweight and obesity trends in Copenhagen schoolchildren from 2002 to 2007. Acta Paediatr 2010;99:1675-1678.

3 Schmidt Morgen C, Rokholm B, Sjoberg Brixval C, Schou Andersen C, Geisler Andersen L, Rasmussen M, Nybo Andersen AM, Due P, Sørensen TIA: Trends in prevalence of overweight and obesity in Danish infants, children and adolescents - are we still on a plateau? PloS one 2013;8:e69860.

4 Olds T, Maher C, Zumin S, Peneau S, Lioret S, Castetbon K, Bellisle, de Wilde J, Hohepa M, Maddison R, Lissner L, Sjoberg A, Zimmermann M, Aeberli I, Ogden C, Flegal K, Summerbell C: Evidence that the prevalence of childhood overweight is plateauing: data from nine countries. Int J Pediatr Obes 2011;6:342-360.

5 Rokholm B, Baker JL, Sørensen TIA: The levelling off of the obesity epidemic since the year 1999 - a review of evidence and perspectives. Obes Rev 2010;11:835-846.

6 de Wilde JA, van Dommelen P, Middelkoop BJ, Verkerk PH: Trends in overweight and obesity prevalence in Dutch, Turkish, Moroccan and Surinamese South Asian children in the Netherlands. Arch Dis Child 2009;94: 795-800.

7 Wang Y: Disparities in pediatric obesity in the United States. Adv Nutr (Bethesda, Md) 2011;2:23-31.

8 Stamatakis E, Wardle J, Cole TJ: Childhood obesity and overweight prevalence trends in England: evidence for growing socioeconomic disparities. Int J Obes 2010;34:41-47.

9 Sundblom E, Petzold M, Rasmussen F, Callmer E, Lissner L: Childhood overweight and obesity prevalences levelling off in Stockholm but socioeconomic differences persist. Int J Obes 2008;32:1525-1530.

10 Baker JL, Sørensen TIA: The Copenhagen School Health Records Register. Scand J Publ Health 2011;39:87-90.

11 Statistics Denmark: Immigrants in Denmark [Danmarks Statistik: Indvandrere i danmark]. Copenhagen, Denmark, 2014

12 Copenhagen Municipality: Copenhagen Municipality Statistics [Københavns kommune Statistikbanken], 2014.

13 Robinson K, Lykke M, Hansen B, Andreasen A, Jeppesen M, Buhelt L, Lau C, Glümer C: Health profile for the region and municipalities 2013 [Sundhedsprofil for region og kommuner 2013]. Copenhagen, Denmark, Forskningscenter for Forebyggelse og Sundhed, Region Hovedstaden, 2014.

14 Cole TJ, Lobstein T: Extended international (IOTF) body mass index cut-offs for thinness, overweight and obesity. Pediatr Obes 2012;7:284-294.

15 Coolidge JA, Herner EB, Bulow SL, Biering-Sorensen S: Overweight and lifestyle among 5 to 8-year old children [Overvægt og livsstil hos 5-8-årige]. Ugeskr Læger 2010;172:2535-2539.

16 Sjoberg A, Hulthen L: Anthropometric changes in Sweden during the obesity epidemic-increased overweight among adolescents of non-Nordic origin. Acta Paediatr 2011;100:1119-1126.

17 Kolle E, Steene-Johannessen J, Holme I, Andersen LB, Anderssen SA: Secular trends in adiposity in Norwegian 9-year-olds from 1999-2000 to 2005. BMC Public Health 2009;9:389.

18 de Wilde JA, Verkerk PH, Middelkoop BJ: Declining and stabilising trends in prevalence of overweight and obesity in Dutch, Turkish, Moroccan and South Asian children 3-16 years of age between 1999 and 2011 in the Netherlands. Arch Dis Child 2014;99:46-51.

19 Krue S, Coolidge J: The prevalence of overweight and obesity among Danish school children. Obesity Rev 2010; 11:489-491.

20 Thibault H, Carriere C, Langevin C, Barberger-Gateau P, Maurice S: Evolution of overweight prevalence among 5-6-year-old children according to socio-economic status. Acta Paediatr 2013;102:273-277.

21 Waters E, Ashbolt R, Gibbs L, Booth M, Magarey A, Gold L, Kai Lo S, Gibbons K, Green J, O’Connor T, Garrard J, Swinburn B: Double disadvantage: the influence of ethnicity over socioeconomic position on childhood overweight and obesity: Findings from an inner urban population of primary school children. Int J Pediatr Obes 2008;3:196-204. 
Pedersen et al.: Ethnic Inequalities in Overweight and Obesity Prevalence among Copenhagen Schoolchildren from 2002 to 2007

22 Khanolkar AR, Sovio U, Bartlett JW, Wallby T, Koupil I: Socioeconomic and early-life factors and risk of being overweight or obese in children of Swedish- and foreign-born parents. Pediatr Res 2013;74:356-363.

23 de Hoog ML, van Eijsden M, Stronks K, Gemke RJ, Vrijkotte TG: Overweight at age two years in a multi-ethnic cohort (ABCD study): the role of prenatal factors, birth outcomes and postnatal factors. BMC Publ Health 2011; 11:611.

24 Reeske A, Spallek J, Bammann K, Eiben G, De Henauw S, Kourides Y, Nagy P, Ahrens W: Migrant background and weight gain in early infancy: results from the German study sample of the IDEFICS study. PloS One 2013; 8:e60648.

25 Kuepper-Nybelen J, Lamerz A, Bruning N, Hebebrand J, Herpertz-Dahlmann B, Brenner H: Major differences in prevalence of overweight according to nationality in preschool children living in Germany: determinants and public health implications. Arch Dis Child 2005;90:359-363.

26 Caprio S, Daniels SR, Drewnowski A, Kaufman FR, Palinkas LA, Rosenbloom AL, Schwimmer JB: Influence of race, ethnicity, and culture on childhood obesity: Implications for prevention and treatment. Obesity (Silver Spring) 2008;16:2566-2577.

27 Statens Serum Institut: Measures from health examinations at school entry [Målinger ved indskolingsundersøgelsen]. Copenhagen, Statens Serum Institut, 2014. 